\title{
Vilen Vagarshovich Azatyan (On the Occasion of His 80th Birthday)
}

DOI: $10.1134 / \mathrm{S} 002315841105017 \mathrm{X}$

On March 25, 2011, Vilen Vagarshovich Azatyan, Corresponding Member of the Russian Academy of Sciences, Doctor of Chemistry, Professor, a member of the editorial board of Kinetics and Catalysis, celebrated his 80th birthday.

Azatyan was born in Yerevan in 1931. In 1954, he graduated from the Faculty of Chemistry of Moscow State University. Now he is the head of the Laboratory of Chain Heterophase Processes, Institute of Structural Macrokinetics and Materials Science, Russian Academy of Sciences.

Azatyan is a prominent physical chemist renowned worldwide for his studies of the mechanisms of gasphase chain reactions. He is a pupil of N.N. Semenov, a Nobel Prize winner in chemistry. For many years, he worked in close collaboration with this great scientist. Azatyan's fundamental works have radically changed our understanding of the physical chemistry of gas combustion, explosion, and detonation. Azatyan discovered that chain branching is the determining factor in gas-phase combustion not only at pressures hundreds of times below atmospheric pressure and not only when there is no overheating, but also at any pressure and any degree of overheating, i.e., under nearly real conditions. The nonisothermal theory of chain processes that is being developed by Azatyan has significantly advanced Academician Semenov's isothermal theory of chain reactions. It has provided a unified explanation for the observed regularities of gas-phase combustion and explosion, of which many were not understood earlier. The investigation of general combustion regularities predicted and discovered by Azatyan, such as the existence of two different modes of developed chain combustion, new critical phenomena, and the effect of admixtures on combustion, explosion and detonation, has evolved into rapidly developing areas of science and technology. Azatyan has laid foundations and has devised methods for chemical control of all modes of gas-phase combustion, including explosion cumulation and detonation breakdown (2002-2005). He has solved the problems of chemical control of combustion, explosion, and detonation, including the explosion safety problem, which is one of the challenges in hydrogen energy. The methods and means suggested by Azatyan for control of the combustion, explosion, and detonation of hydrogen- and methane-containing mixtures have passed acceptance tests in Moscow and in a testing drift in Kemerovo and have received a positive resolution from the authorized interministerial commission. These works are particularly important in view of the accidents in Russian mines and at the Fukushima nuclear power plant in Japan.

Azatyan's pioneering works in identification of free atoms and radicals and their reactions in flame using visible, EPR, and LMR spectroscopy, mathematical modeling, and quantum chemical calculations are renowned worldwide. These works have evolved into investigation of fast reactions in which atomic reactants displace atoms from molecules and into investigation of the role of these reactions in combustion and pyrolysis.

Azatyan is the author of over 500 scientific works, including 30 patents and inventor certificates and two monographs (in coauthorship with Prof. E.T. Denisov). One of the latter was published abroad. Azatyan is an active science manager and pedagogue. $\mathrm{He}$ is a member of the Combustion and Explosion Bureau of the Scientific Council of the Russian Academy of Sciences, a IUPAC member, a member of the scientific and technical council of the All-Russian Research Institute for Fire Protection (Ministry for Civil Defense, Emergencies, and Elimination of Consequences of Natural Disasters), and a member of the editorial boards of Russian Journal of Physical Chemistry and Kinetics and Catalysis. For his practical achievements, Azatyan was awarded with the Kemerovo oblast governor medal "For Outstanding Contribution to the Development of Kuzbass" and with the Moscow oblast governor badge "Gratitude."

Azatyan is full of new creative plans and continues to work actively and fruitfully in science.

The editorial board of Kinetics and Catalysis sincerely congratulates Vilen Vagarshovich on the occasion of his jubilee and wishes him good health and every success in his creative activities. 